\title{
Interactions of mRNAs and gRNAs involved in trypanosome mitochondrial RNA editing: Structure probing of a gRNA bound to its cognate mRNA
}

\author{
LAURA E. YU ${ }^{\mathbf{1}}$ and DONNA J. KOSLOWSKY ${ }^{1,2}$ \\ ${ }^{1}$ Cell and Molecular Biology Program and ${ }^{2}$ Department of Microbiology and Molecular Genetics, Michigan State University, East Lansing, \\ Michigan 48824, USA
}

\begin{abstract}
Expression of mitochondrial genes in Trypanosoma brucei requires RNA editing of its mRNA transcripts. During editing, uridylates are precisely inserted and deleted as directed by the gRNA template to create the protein open reading frame. This process involves the bimolecular interaction of the gRNA with its cognate pre-edited mRNA and the assembly of a protein complex with the enzymatic machinery required. While a considerable amount of work has been done identifying the protein components of the editing complex, very little is known about how a functional editosome is assembled. In addition, the importance of RNA structure in establishing a functional editing complex is poorly understood. Work in our lab suggests that different mRNA/gRNA pairs can form similar secondary structures suggesting that a common core architecture may be important for editosome recognition and function. Using solution structure probing, we have investigated the structure of the initiating gRNA, gCYb-558, in the mRNA/gRNA complex with pre-edited apocytochrome $b$ mRNA. Our data indicate that the stem-loop formed by the guiding region of the gRNA alone is maintained in its interaction with the pre-edited message. In addition, our data suggest that a gRNA stem-loop structure is maintained through the first few editing events by the use of alternative base-pairing with the U-tail.
\end{abstract}

Keywords: Trypanosoma brucei; apocytochrome b; post-transcriptional processing; RNA-RNA interactions; RNA structure; RNA editing

\section{INTRODUCTION}

In kinetoplastid protozoa, guide RNAs (gRNAs) serve as templates for the precise insertion and deletion of uridylates during RNA editing of the mitochondrial mRNA transcripts. This post-transcriptional process produces translatable mRNAs by creating the open reading frames as well as initiation and termination signals. In addition, there is a transcript-specific mechanism that regulates editing during the life cycle of the parasite. The gRNAs are key components of the reaction, as they provide the information for the nucleotide (nt) alterations and direct the cleavage and ligation events (Simpson et al. 2004; Stuart et al. 2005). Guide RNAs have an average length of 50-70 nt

Reprint requests to: Donna J. Koslowsky, Department of Microbiology and Molecular Genetics, Room 2209, Biomedical Physical Sciences Building, East Lansing, MI 48824-4320, USA; e-mail: koslowsk@msu.edu; fax: (517) 353-8957.

Article published online ahead of print. Article and publication date are at http://www.rnajournal.org/cgi/doi/10.1261/rna.3406. and consist of three functional elements. Contained within the $5^{\prime}$ end of gRNAs is a short sequence known as the gRNA anchor, a 5- to 21-nt region that base-pairs with a particular mRNA just $3^{\prime}$ of the editing domain. The second element, the guiding region, serves as a template for the editing process and is complementary (allowing G-U base pairs) to the mature mRNA. Finally, at the $3^{\prime}$ end of the gRNA is a poly-uridylate tail (U-tail) that is added post-transcriptionally (Blum and Simpson 1990; Blum et al. 1990).

The latest model for RNA editing in trypanosomes involves $>20$ proteins that form a complex structure called the editosome around an mRNA/gRNA pair (Simpson et al. 2004; Stuart et al. 2005). The insertion and deletion of uridines occur through successive rounds of enzymatic reactions coordinated by the editosome and templated by the gRNA (Blum and Simpson 1990; Blum et al. 1990; Seiwert and Stuart 1994; Adler and Hajduk 1997). Significant progress has been made in identifying proteins involved in the editing reaction, including both proteins in the complex as well as proteins that appear to be 
accessory factors that transiently act during the editing process (Koller et al. 1997; Missel et al. 1997; MadisonAntenucci et al. 1998; Vanhamme et al. 1998; Hayman and Read 1999; Aphasizhev and Simpson 2001; McManus et al. 2001; Panigrahi et al. 2001a,b; Rusche et al. 2001; Schnaufer et al. 2001; Aphasizhev et al. 2002; Aphasizhev et al. 2003a,b; Panigrahi et al. 2003a,b; Pelletier and Read 2003). However, despite this progress, very little is known about how the editing complex is assembled onto specific RNAs. No conserved sequence domains have been found in mRNAs, and the only conserved sequence domain shared between the gRNAs is the U-tail. Previous work in this laboratory suggests that different mRNA/gRNA pairs can form similar structures (Leung and Koslowsky 1999), and we believe that structure recognition may be important for efficient editosome assembly with the mRNA/gRNA pair.

In previous studies, we used a RNA folding program to look for conserved structures between three different mRNA/gRNA pairs. The predicted secondary structures for these mRNA/gRNA pairings incorporated a distance constraint based on photoaffinity cross-links (Leung and Koslowsky 1999). Further structure analyses for the apocytochrome $b$ mRNA/gRNA complex were undertaken to look at mRNA/gRNA structure as editing progresses up through the third editing site. The predicted secondary structures for these mRNA/gRNA pairings are based on photoaffinity cross-linking studies of the $5^{\prime}$ and $3^{\prime}$ ends of $\mathrm{NgCYb}-558$ that were mapped along 5'CYbUT (first $88 \mathrm{nt}$ of CYb mRNA), 5'CYbPES1T (edited through site 1), and 5' CYbPES3T (edited through site 3) (Leung and Koslowsky 2001b). In addition, a solution structure probing study of $5^{\prime} \mathrm{CYbUT}$ while paired with $\mathrm{NgCYb}-558$ or $\mathrm{NgCYb}-$ 558sU (no U-tail) was done (Leung and Koslowsky 2001a). With the data from these studies, we proposed a secondary structure model that includes the following features: a gRNA/mRNA anchor helix, a U-tail/mRNA helix, and a gRNA stem-loop (Fig. 1A; Leung and Koslowsky 1999, $2001 \mathrm{a}, \mathrm{b})$. The predicted structure of the gRNA interaction with the partially edited mRNA was particularly interesting

A

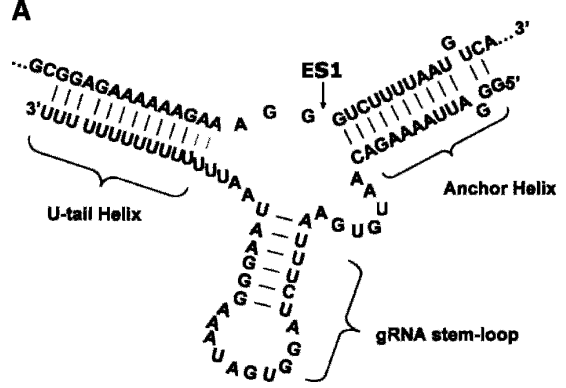

B

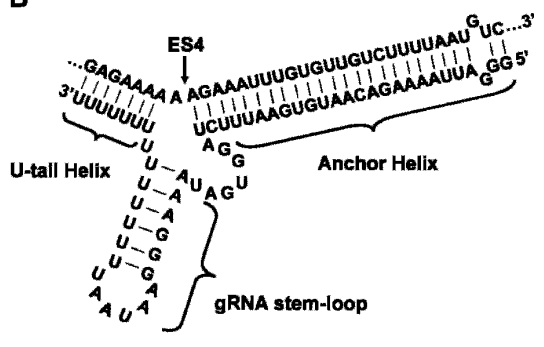

FIGURE 1. The predicted models for mRNA/gRNA complex secondary structure have three helices: an mRNA/gRNA anchor helix, a gRNA stem-loop within the guiding region, and a U-tail/mRNA duplex. (A) CYbU-NgCYb-558 pair with the first editing site just 5' (mRNA) of the anchor indicated by ES1. (B) CYbPES3-NgCYb-558 pair with the fourth editing site just $5^{\prime}$ (mRNA) of the anchor indicated by ES4. because it suggests that the U-tail could function to maintain the gRNA stem-loop during the first few editing events (Fig. 1B). The focus of this article is on the solution structure probing of the secondary structure of the gRNA, $\mathrm{NgCYb}-558$, paired with unedited and partially edited mRNAs, as we would like to understand how the gRNA structure may be changing during the early steps of the editing process. In addition, we have also probed the structure of the partially edited mRNA, CYbPES3, to corroborate our gRNA structure data. Our data indicate that the stem-loop formed by the guiding region of the gRNA alone is maintained in its interaction with the preedited message as predicted in the computer models. In addition, our data support the predicted structure for the gRNA interaction with its partially edited mRNA in that the gRNA stem-loop structure appears to be maintained through the first few editing events by the use of alternative base-pairing with the U-tail.

\section{RESULTS AND DISCUSSION}

\section{Cross-linked RNAs used for solution structure probing}

Editing of the apocytochrome $b$ mRNA is developmentally regulated with the insertion of 34 uridylates at 13 sites near its $5^{\prime}$ end. The editing process that creates the CYb initiation codon occurs preferentially during the procyclic (insect) and stumpy bloodstream stages of the trypanosome life cycle (Feagin et al. 1987; Feagin and Stuart 1988). In these experiments, we used modified versions of $5^{\prime} \mathrm{CYbUT}$ (Koslowsky et al. 1992, 1996). CYbU (U, unedited) is identical in sequence to $5^{\prime} \mathrm{CYbUT}$ except for the deletion of $12 \mathrm{nt}$ at the $5^{\prime}$-most end (Fig. 2A) and is composed of $88 \mathrm{nt}$ from the $5^{\prime}$ end of the apocytochrome $b$ mRNA (beginning at +13 ) including all 13 editing sites as well as a 24-nt vector tag at the $3^{\prime}$ end. The partially edited substrate, CYbPES3 (PES, partially edited through site 3 ), is identical to $\mathrm{CYbU}$ except for the six uridines added so that the first three editing sites are fully edited (Fig. 2B). Our gRNA construct $\mathrm{NgCYb}-558$ (Fig. 2C) is very similar to wild-type gCYb-558 and two other redundant gRNAs, gCYb560A, B. All three gRNAs can act as the editing initiating gRNA that direct the editing of the first seven editing sites (Riley et al. 1994). NgCYb-558 is 59 nt long including a 15-nt U-tail that is added via ligation with T4 DNA ligase and a bridging deoxyoligonucleotide (Moore and Sharp 1992; Leung and Koslowsky 2001a).

The secondary structure of gCYb-558 was reported by Schmid et al. (1995) and described as two thermodynamically unstable hairpin loops separated by a single-stranded region. The smaller 
A CYbU Sequence (mRNA transcript): GGUUAUAAAUUUUAUAUAAAAGCGGAGAAAAAAGAAAGGGUCUUUUAAUGUCAGGUUGU UUAUAUAGAAUAUAUGGauccacuaguucuagagcggcc

CYbU aligned to NgCYb-558:

----GGUUAUAAAUUUUAUAUAAAAGCGGAGAAAAAGAAAGGGUCUUUUAAUGUCAGGUUGUUUAUAU NgCYb-558UUUUUAAUAAGGGAAAUAGUGGAUCUUUAAGUGUAACAGAAAUUUAGG

B CYbPES3 Sequence (mRNA transcript):

GGUUAUAAAUUUUAUAUAAAAGCGGAGAAAAAAGAAAuUuGuGuUGUCUUUUAAUGUCA GGUUGUUUAUAUAGAAUAUAUGGauccacuaguucuagagcggcc

CYbPES3 aligned to $\mathrm{NaCYb}-558$ :

GGUUAUAAAUUUUAUAUAAAAGCGGAGAAAAAA GAAAuUuGuGuuGUCUUUUARUGUCAGGUUGUUUAD -

C

NgCYb-558 sequence:

IgCYb558--5' GGG-AUUAAAAGACAAUGUGAAUUUCUAGGUGAUAAAGGGAAUAAUUAUUUUUUUUUUUU

gcrb [560A] 5' GGAGAUAGUAAAAGACAAUGUAGAUUUCOUGAGUAAUGGGGAGGAUAACUACUCUCUAGGGAA. .

FIGURE 2. Sequence and alignment of the gRNA/mRNA substrate pairs. (A) The full CYbU (U, unedited) transcript and CYbU aligned to $\mathrm{NgCYb}-558$ is shown. $\mathrm{CYbU}$ is composed of $88 \mathrm{nt}$ from the $5^{\prime}$ end of the apocytochrome $b$ mRNA (beginning at +13 ), including all 13 editing sites as well as a 24-nt vector tag at the $3^{\prime}$ end. (B) The CYbPES3 (PES, partially edited through site 3) transcript and CYbPES3 aligned $^{-}$to NgCYb-558 is shown. The partially edited mRNA, CYbPES3, is identical to CYbU except for the six uridines (lowercase U's) added so that the first three editing sites are fully edited. The complementarity between the gRNA and mRNA in the anchor duplex (bold) is shown with (\#) mismatched sequence, (:) GU base pair, (|) Watson-Crick base-pairing. The arrow indicates the position of the introduced cross-link. (C) The NoCYb-558 sequence aligned with wild type initiating $\mathrm{CYb}$ gRNAs, gCYb-558, and $\mathrm{gCYb}[560 \mathrm{~A}]$ sequences. $\mathrm{NgCYb}-558$ is $59 \mathrm{nt}$ long, including a $15-\mathrm{nt}$ uridylate-tail (U-tail) and has $4 \mathrm{nt}$ differences compared to wild-type gCYb-558. (*) matching sequence, (-) gap. $\mathrm{C}_{25}$, according to $\mathrm{NgCYb}-$ 558 , is bold and underlined in all the gRNAs.

hairpin at the $5^{\prime}$ end contains the anchor binding sequence that selects the mRNA for editing. The guiding region forms a longer stem-loop and the U-tail appears to be single-stranded (Schmid et al. 1995). The sequence of the gRNA used in this study differs slightly from the gCYb-558 used in the Schmid et al. (1995) study. One significant difference is that a cytosine residue replaces a uridine at position 25, a nucleotide change also seen in wild-type gCYb-560A, B (Fig. 2C). This $U$ to $C$ change creates a strong $\mathrm{G}-\mathrm{C}$ base pair within the guiding region that appears to stabilize a single gRNA stem-loop that differs slightly from the Schmid et al. (1995) report.

In order to determine the structure of the gRNA in its interaction with its cognate mRNA, we used solution structure probing techniques and $3^{\prime}$-end-labeled gRNAs that had been cross-linked to the cognate mRNA at the $3^{\prime}$ end of the anchor duplex (mRNA orientation). It has been previously shown that these structures can assemble with enzymatically active editing proteins and are biologically relevant (Leung and Koslowsky 2001a).

Cross-linked substrates were generated by transcribing gRNAs in the presence of guanosine $5^{\prime}$-monophosphoro- thioate (GMPS) (Burgin and Pace 1990; Harris and Christian 1999). The gRNAs were 3 'end-labeled using T4 RNA ligase and $\left[5^{\prime}{ }^{32} \mathrm{P}\right]$ cytidine $3^{\prime}, 5^{\prime}$-bisphosphate (pCp) when probing the gRNA; the mRNAs were $5^{\prime}$ end-labeled using T4 Kinase and $\left[\gamma_{-}{ }^{32} \mathrm{P}\right] \mathrm{rATP}$, when probing the mRNA structure. After labeling, the thiol group of GMPS at the $5^{\prime}$ end of the gRNA was coupled to azidophenacyl bromide (APA) and UV cross-linked as previously described (Burgin and Pace 1990; Leung and Koslowsky 1999). The resultant cross-link is covalently linked to the mRNA at the $3^{\prime}$ end (mRNA orientation) of the gRNA/ mRNA anchor duplex (Fig. 2A,B). Therefore, these crosslinked RNAs maintain the anchor duplex, an element required for the process of editing. The higher order structure of NgCYb-558 cross-linked to its cognate mRNA was probed using ribonuclease accessibility experiments (Fig. 3). Single-stranded, nonstacked conformations were monitored using ribonucleases T1 (G specific), T2 (slight preference for A), and Mung Bean Nuclease (MBN) (slight preference for A). RNase V1 was used to determine nucleotides involved in base-paired helical interactions or in stacked, structured elements (Lowman and Draper 1986). For comparative purposes, an analysis of the structure of the free $\mathrm{NgCYb}-558$ was compared to the structure of the gRNA cross-linked to either unedited CYb (CYbU) or to a partially edited CYb (CYbPES3). In addition, to complement the gRNA data, the structure of CYbPES3 cross-linked to both NgCYb-558 and NgCYb$558 \mathrm{sU}$ (NgCYb-558 lacking a U-tail) was also examined. The mRNA secondary structure was probed by both ribonuclease accessibility and chemical reactivity (diethyl pyrocarbonate (A, N7)) (Figs. 4, 5). The data were used to construct secondary structure models with the data summarized in Figure 6. In the summary figures the intensity of the cut is represented by large or small symbols for each enzyme or chemical. The high intensity cleavages (large symbols) represent hot spots that are unprotected by secondary and tertiary interactions. Cleavages of medium and low intensity were harder to classify and may include both sites where tertiary structure incompletely blocks access and some secondary cuts that are not reflective of the native structure (small symbols). In addition, the lower intensity cleavages could be due to alternative structures formed by a small percentage of the RNA population. However these cleavages appeared consistently in all gels.

\section{Structure of the $\mathrm{NgCYb}-558$ anchor region}

Structure probing of unpaired $\mathrm{NgCYb}-558$ by singlestrand-specific nucleases indicates that the anchor region (G1-C13) is mostly single-stranded (Fig. 3). Under our conditions $\left(100 \mathrm{mM} \mathrm{KCl}\right.$ and $1 \mathrm{mM} \mathrm{MgCl}_{2}$ ), distinct cleavage products were clearly visible in the anchor region using MBN, RNase T2, and RNase T1. As expected, when 


\section{A Mung Bean Nuclease}

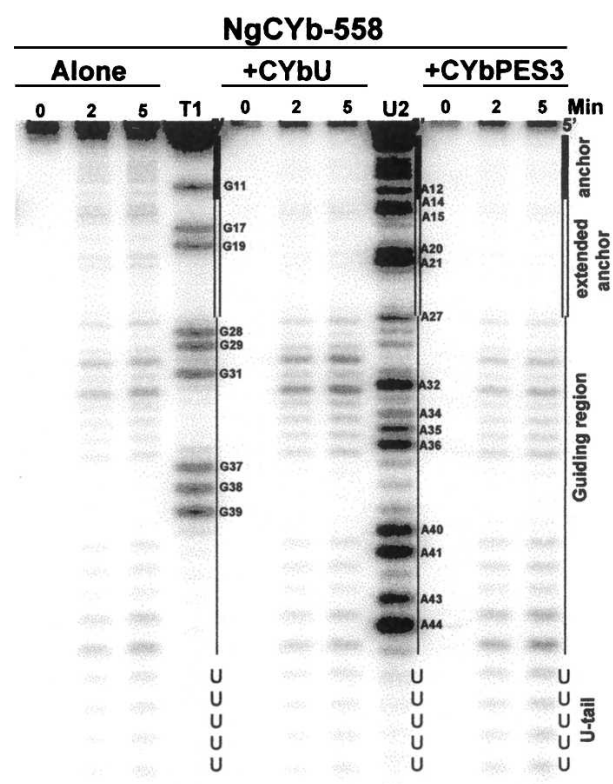

C RNase T1

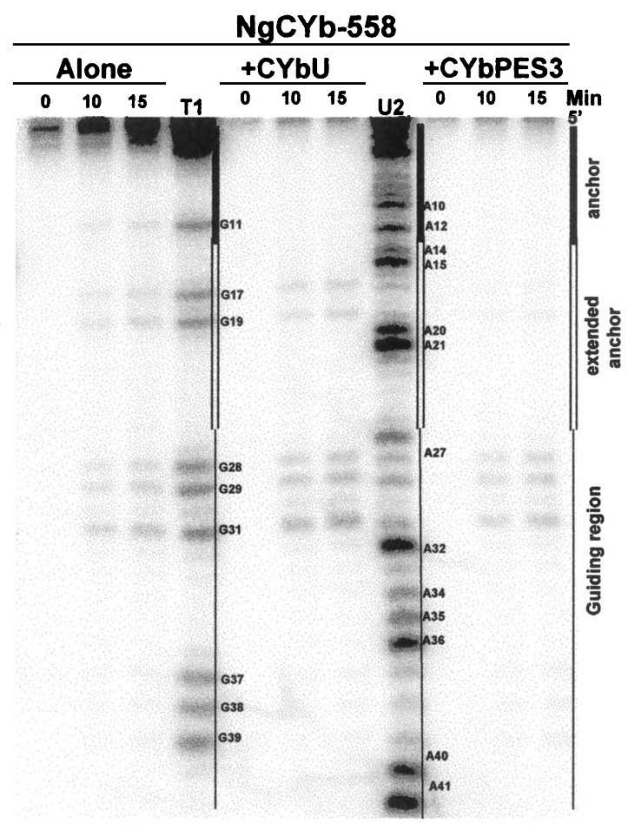

\section{B RNase T2}

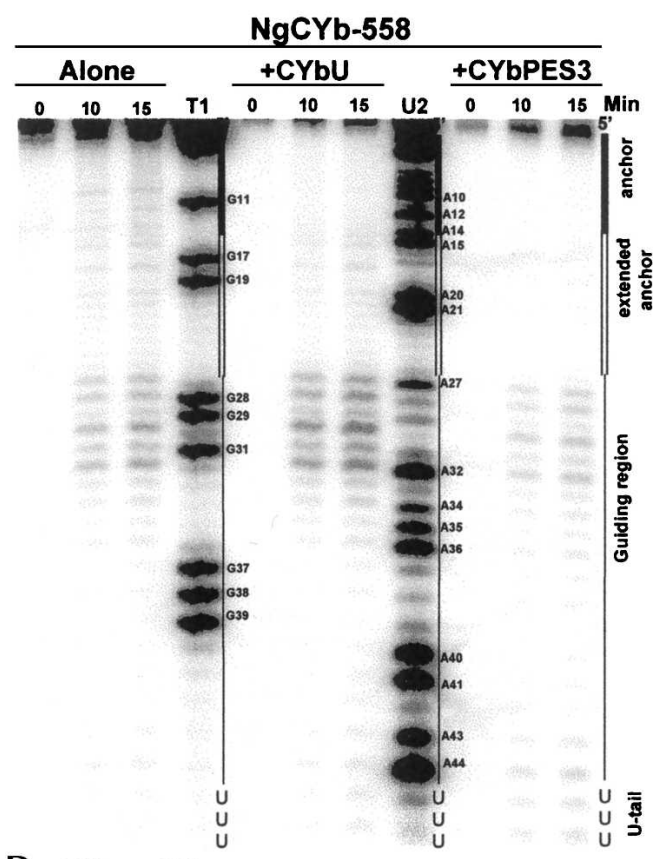

D RNase V1

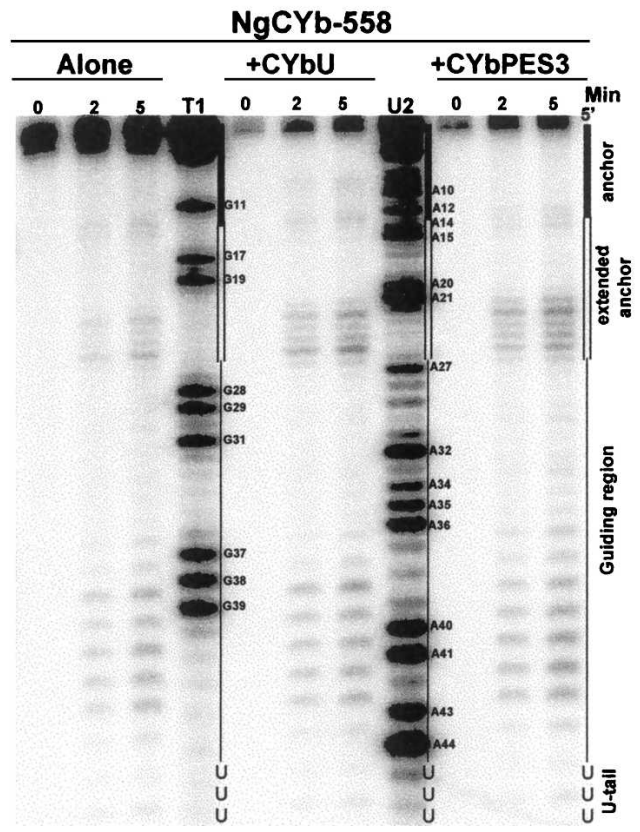

FIGURE 3. Structure probing of the gRNA, NgCYb-558. Each solution structure probing gel has three sections showing the digestion pattern of $\mathrm{NgCYb}-558$ alone, $\mathrm{NgCYb}-558$ cross-linked to $\mathrm{CYbU}$ (+CYbU), and NgCYb-558 cross-linked to CYbPES3 (+CYbPES3). Digestion times in minutes are shown at the top. RNase T1 and U2 ladders with nucleotide numbers are indicated. A line diagram indicating the anchor (bold line), extended anchor (double line), guiding region (thin line), and U-tail of the gRNA is shown next to each digestion pattern. (A) Mung bean nuclease gel, single-strand specific. (B) RNase T2, single-strand specific. $(C)$ RNase T1, single-strand guanosine specific. (D) RNase V1, double-strand specific.

the gRNA was cross-linked to its cognate mRNA (+CYbU and + CYbPES3), the anchor duplex formed and was no longer sensitive to the single-strand-specific RNases. The RNase V1 (V1) sensitivity pattern generally complemented these data. We did observe two V1 cleavages in the unpaired gRNA at positions A12 and C13 (Fig. 3D), located near the end of the anchor region, that were also sensitive to the single-strand-specific nucleases. 
A Mung Bean Nuclease

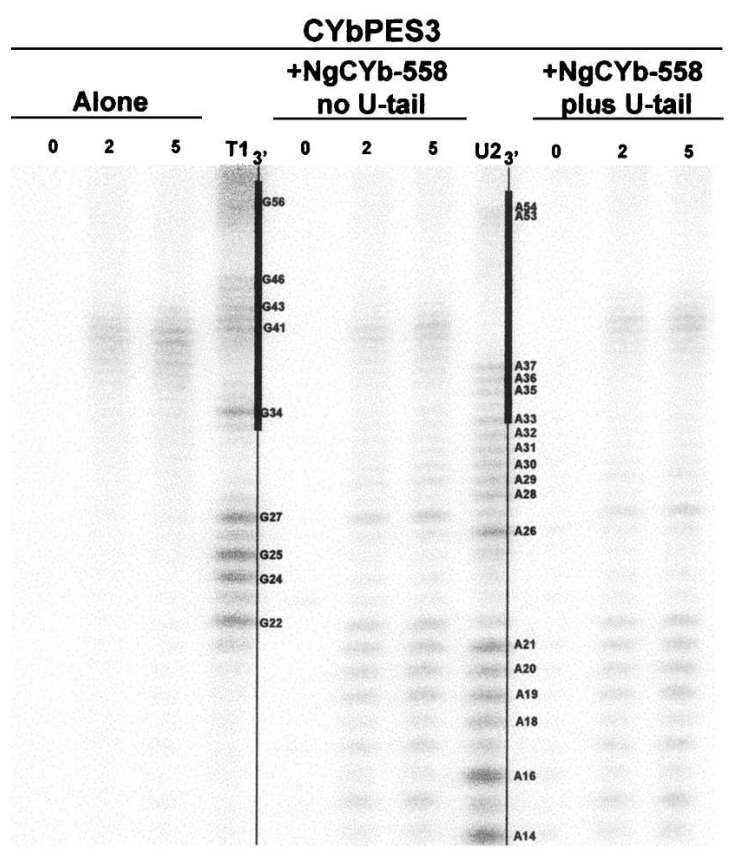

C RNase T1

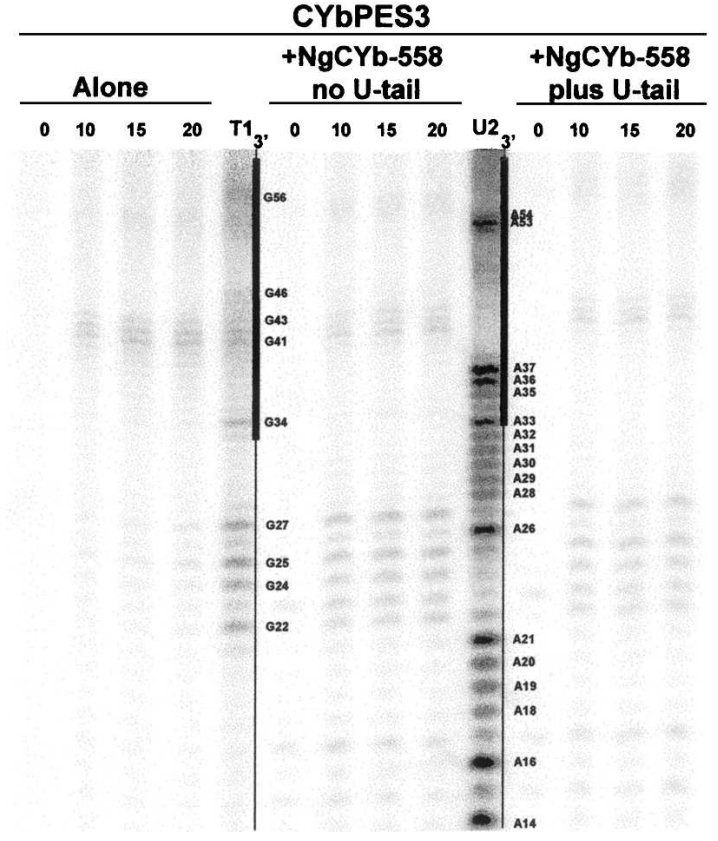

B RNase T2

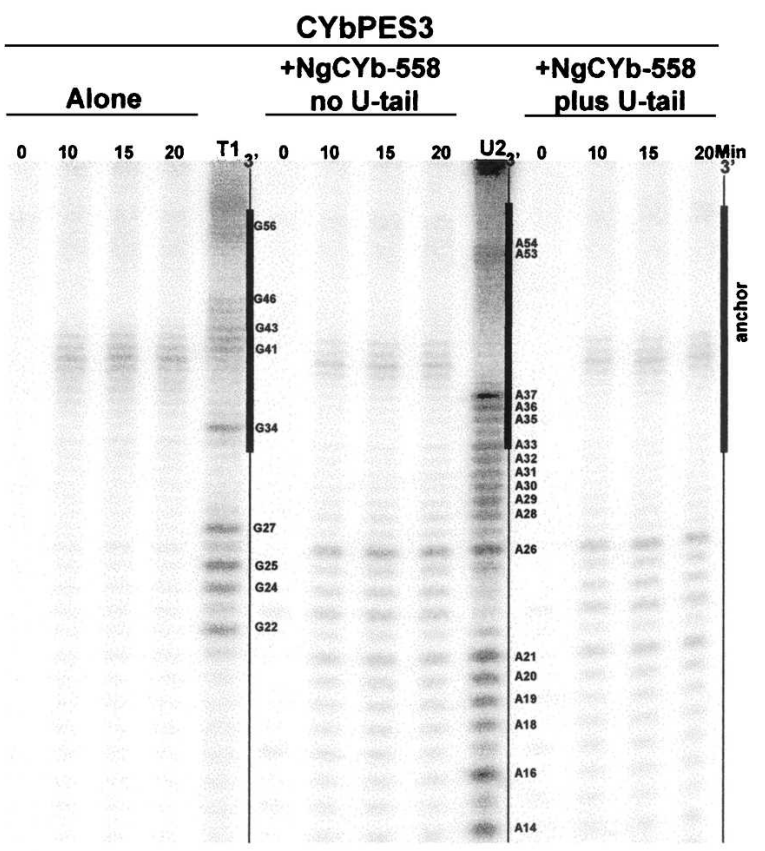

D RNase V1

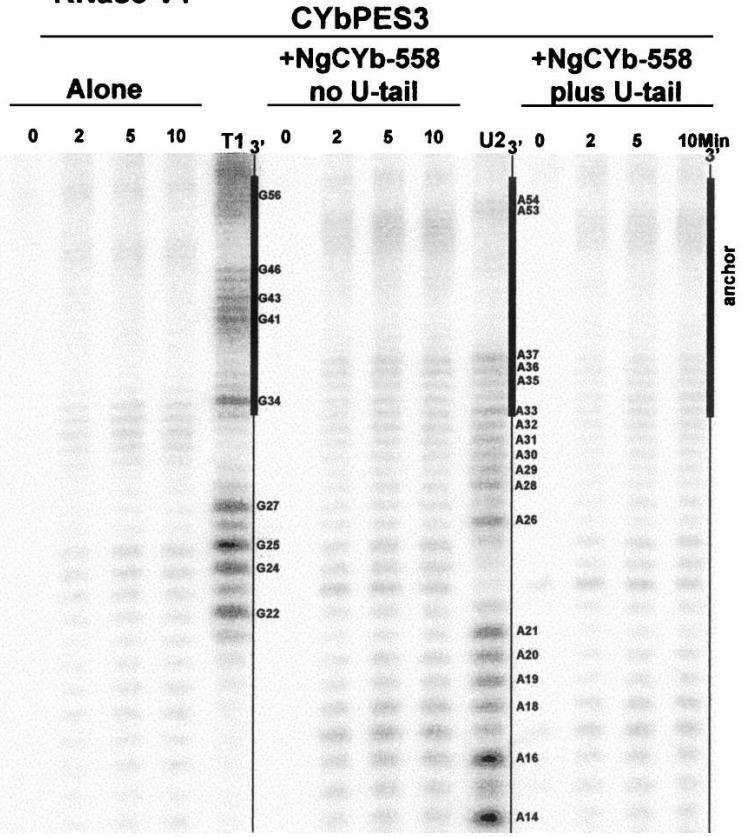

FIGURE 4. Structure probing of the partially edited CYb mRNA, CYbPES3. Each solution structure probing gel has three sections showing the digestion pattern of CYbPES3 alone, CYbPES3 cross-linked to NgCYb-558sU (no U-tail), and CYbPES3 cross-linked to $\mathrm{NgCYb}-558$. Digestion times in minutes are shown at the top. RNase $\mathrm{T} 1$ and U2 ladders with nucleotide numbers are indicated. A diagram of the mRNA is next to each digestion pattern showing the orientation $3^{\prime}$ to $5^{\prime}$ with the extended anchor (bold line). (A) Mung bean nuclease gel, single-strand specific. (B) RNase T2, single-strand specific. (C) RNase T1, single-strand guanosine specific. (D) RNase V1, double-strand specific.

While V1-sensitive cleavages were clearly visible within the anchor duplex of the paired gRNA (+CYbU; Fig. 3) and within the extended anchor duplex (+CYbPES3; Fig. 3), it was interesting that the cleavages were concentrated in the $5^{\prime}$ half (mRNA orientation) of the anchor duplex. Lack of cleavage in the G1-A7 region may be due to the presence of the cross-link. For NgCYb-558 paired with CYbU, V1 cleavages within the anchor were surprisingly weak and 


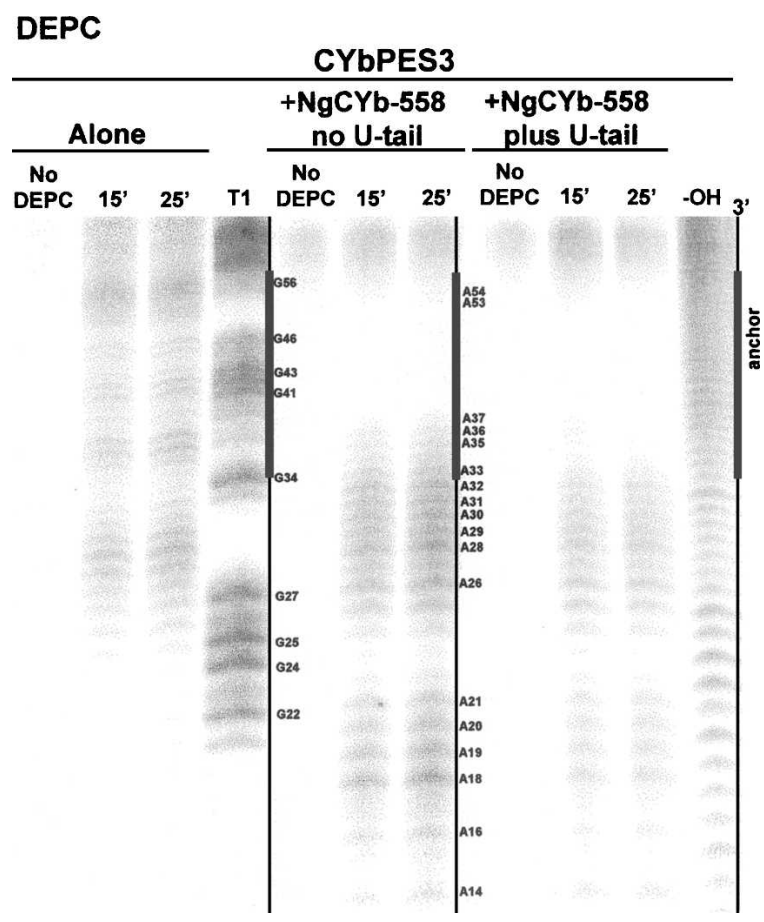

FIGURE 5. Chemical structure probing of the partially edited $\mathrm{CYb}$ mRNA, CYbPES3. The diethyl pyrocarbonate (DEPC) chemical structure probing gel has three sections showing the difference in digestion pattern of CYbPES3 alone, CYbPES3 cross-linked to $\mathrm{NgCYb}-558 \mathrm{sU}$ (no U-tail), and CYbPES3 cross-linked to NgCYb558. Digestion times in minutes are shown at the top. RNase T1 and U2 ladders with nucleotide numbers are indicated; an alkaline hydrolysis ladder $(-\mathrm{OH})$ was included as well. A diagram of the mRNA is next to each digestion pattern showing the orientation $3^{\prime}$ to $5^{\prime}$ with the extended anchor (bold line).

limited to A8-C13 (Fig. 3D). This region was also very poorly cleaved in the $\mathrm{NgCYb}-558 / \mathrm{CYbPES} 3$ pairing, where the anchor is extended to U26. In this extended anchor, strong V1 cleavages were observed in the $3^{\prime}$ most end of the duplex (A21-U26; Fig. 3D). The limitation of strong RNase V1 cleavage to the A21-U26 region of the extended anchor duplex was unexpected and suggests that most of the anchor duplex may be protected by tertiary interactions.

\section{Structure of $\mathrm{NgCYb}-558$ guiding region}

Secondary structure analyses of several unpaired gRNAs indicate that the guiding regions (nucleotides between the 5' anchor and 3' U-tail) form a gRNA stem-loop element (Schmid et al. 1995). In our digests of unpaired $\mathrm{NgCYb}-$ 558, we also observe the presence of a gRNA stem-loop (Fig. 6). Weak but consistent single-strand-specific cleavages at nt A14-A20 indicate that the area adjacent to the anchor (containing the template for the first few editing sites) is single-stranded until nt A21 (Fig. 3). Distinct cleavages using the single-strand-specific RNases were also observed for nt A27-A36. The lack of single-stranded specific cleavages in the U22-U26 and G37-G39 flanking regions and weak cleavages of A41 to U42 suggested that the U22-U42 region base-pairs to the G37-U42 region and forms a stem with a large 10-nt terminal loop (A27-A36) (Fig. 3). The presence of this stem-loop is confirmed by the pattern of V1 sensitive cleavages of nt U22-26 and nt G37U42 (Fig. 3D). When the gRNA was paired with the unedited mRNA (+CYbU) or the partially edited CYbPES3, the patterns of nuclease cleavages for the guiding region were almost identical to those observed in the gRNA alone (Fig. 3). This was particularly surprising for the $\mathrm{NgCYb}-$ $558 /$ CYbPES3 pair, as the anchor duplex has doubled in length ( 26 bp vs. $13 \mathrm{bp}$ ) and has incorporated the U22-U26 5 '-stem region from our gRNA stem-loop. All three gRNA structures (gRNA alone, paired with CYbU, and paired with CYbPES3) showed a pattern of single-strand RNase sensitivity in the A27-A36 region flanked by RNase V1 sensitivity in the A21-U26 and G38-A42 regions (Figs. 3, 6). While the RNase cleavage patterns of the guiding region were very similar, we did see some consistent differences. For the $\mathrm{NgCYb}-558 / \mathrm{CYbU}$ pair, weak but consistent MBN and RNase T2 cleavage sensitivity could be seen in A15 to U18. In addition, both G17 and G19 are accessible to RNase $\mathrm{T} 1$, suggesting the presence of a 5- to 6-nt bulge between the anchor duplex and the gRNA guiding region stem (Fig. $3 \mathrm{~A}-\mathrm{C})$. The corresponding region is completely protected when the gRNA is paired with CYbPES3, as would be expected with the extension of the anchor duplex to U26. The NgCYb-558 paired to CYbPES3 also showed a subtle difference in the pattern of RNase V1 cleavage in the A21U26 region (Fig. 3). Both the gRNA alone and gRNA paired with unedited $\mathrm{CYb}$ had stronger RNase V1 cleavages at U22 and $\mathrm{C} 25$ when these nucleotides are forming the initial gRNA stem-loop. When the gRNA is paired with CYbPES3 and nt U22 and C25 have become part of the anchor duplex, the U22 V1 cleavage appears to be intense, while the other sites in this region having relatively equal cleavage intensities (Fig. 3D). We also observed a slight increase in the RNase V1 sensitivity in the U33-G37 region for the gRNA when paired to CYbPES3 (Fig. 3D, panel 3). In addition, the single-strand-specific cleavages in the A27A36 region were consistently less intense for the gRNA when paired with CYbPES3 (Fig. 3). The cleavage patterns of the gRNA were incorporated into summary figures based on computer modeling of the predicted secondary structure of the gRNA alone (Fig. 6A) as well as the mRNA/gRNA complex with both unedited and partially edited mRNA (Fig. 6B,C). Our cleavage patterns support the computer predicted models and illustrate the change in gRNA structure produced by editing of the mRNA. The unpaired gRNA forms a gRNA stem-loop that is maintained when the gRNA pairs with the pre-edited mRNA (Fig. 6A,B). Editing of the first three sites extends the anchor duplex by $13 \mathrm{bp}$, incorporating one side of the gRNA stem into the anchor helix. The nucleotides that were located within the terminal loop remain single-stranded, but are now located 


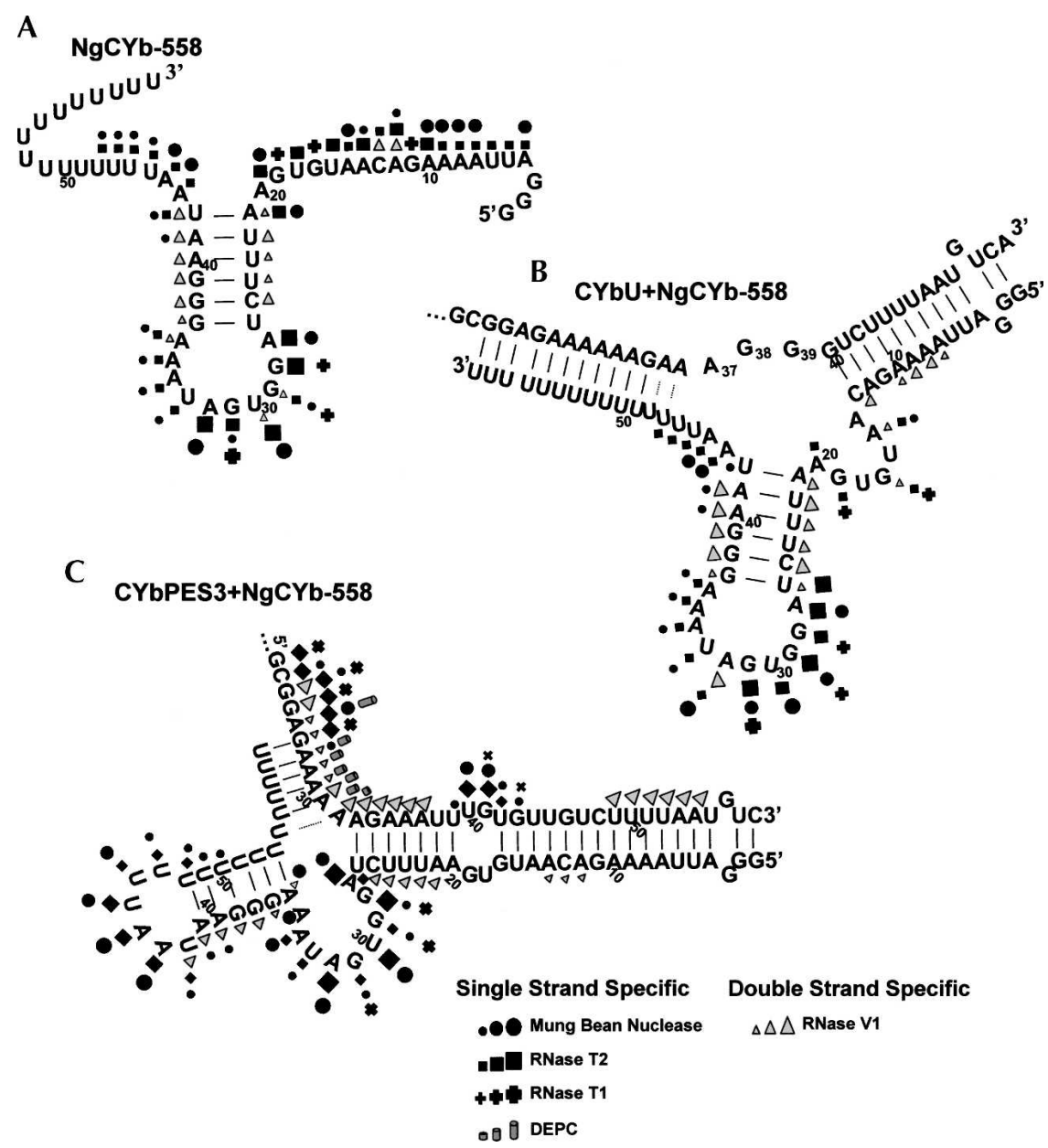

FIGURE 6. Summary figures from solution structure probing gels that show predicted secondary structures with cleavages from all four nucleases and DEPC chemical. Three sizes of symbols indicate the intensity of cleavage. Circles indicate mung bean nuclease (single-strand specific) cleavages, squares indicate RNase T2 (single-strand specific) cleavages, crosses indicate RNase T1 (single-strand guanosine specific) cleavages, cylinders indicate DEPC (singlestrand adenosine specific), and triangles indicate RNase V1 (double-strand specific) cleavages. (A) NgCYb-558 alone. (B) CYbU/NgCYb-558 complex. (C) CYbPES3/NgCYb-558 complex.

within a bulge region between the anchor duplex and the new gRNA stem-loop. However, a new gRNA stem-loop is formed by alternative base-pairing of A36-A41 with part of the U-tail (Fig. 6C).

\section{Structure of CYbPES3}

In order to corroborate the structure of the gRNA interaction with the partially edited CYbPES3, we also probed the secondary structure of CYbPES3. For comparative purposes, we investigated the structure of CYbPES3 alone as well as its structure when paired with $\mathrm{NgCYb}-558$ with and without the U-tail. In previous work, the structure of the unedited $\mathrm{CYb}$ mRNA alone was found to be a strongly base-paired stem-loop with the first three editing sites contained in a terminal 5-nt loop (A35-U41) (Leung and Koslowsky 2001a). Editing of the first three sites appears to add an additional six uridines to the terminal loop but otherwise does not significantly change the structure found within the stem region (Figs. 4, 5, 7). This is shown (Figs. 4, 5) by MBN (U42-A36), T2 (U42-U38), and T1 (G41, G43) cleavages within the terminal loop (Figs. 4, 7). RNase V1 data complement the data from the singlestranded nucleases (Fig. 4D, 7).

The structure of CYbPES3 crosslinked to its cognate gRNA (NgCYb558) was much more difficult to interpret. Pairing of the partially edited mRNA with its gRNA clearly changed the structure of the mRNA, making it much more susceptible to the singlestrand-specific nucleases (Fig. 4). Interestingly, while the anchor duplex region was mostly protected, we did observe distinct cleavages in the U39-G43 regions for all three single-strand-specific nucleases (Fig. 4). This corresponds to a run of four G:U base pairs within the anchor duplex created by the second and third RNA editing events. Within this region, the RNase V1 analyses did complement the single-strandspecific nucleases with distinct V1 cleavages localized in two regions flanking the U39-G43 region: A33-A37 and U47-A54. No corresponding singlestrand nuclease sensitivity was observed when probing the gRNA; however, this region was also protected in our RNase V1 analyses, suggesting that tertiary interactions may be restricting nuclease access. It has been proposed that $\mathrm{G}-\mathrm{U}$ base pairs may locally destabilize helical regions, widening the major groove (Chow et al. 1992).

Upstream of the anchor duplex, nt A14-G27 were also much more sensitive to the single-stranded nucleases, indicating that interaction with the gRNA opens up the stable stem-loop structure of the mRNA (Figs. 4, 6C). Surprisingly, the run of six adenosine residues (A28-A32), located just $5^{\prime}$ of the anchor duplex, was clearly protected from cleavage by both MBN and RNase T2 (Fig. 4). RNase V1 cleavages were observed within this region. However, RNase V1 cleavages were also observed for nt A14-G27, which also show distinct sensitivity to the single-stranded nucleases (Fig. 4D). The ability of RNase V1 to cleave stacked, highly structured regions and junctions found between two helices may explain some of the overlapping nuclease sensitivity (Lowman and Draper 1986). In an effort to resolve our conflicting nuclease results, additional 


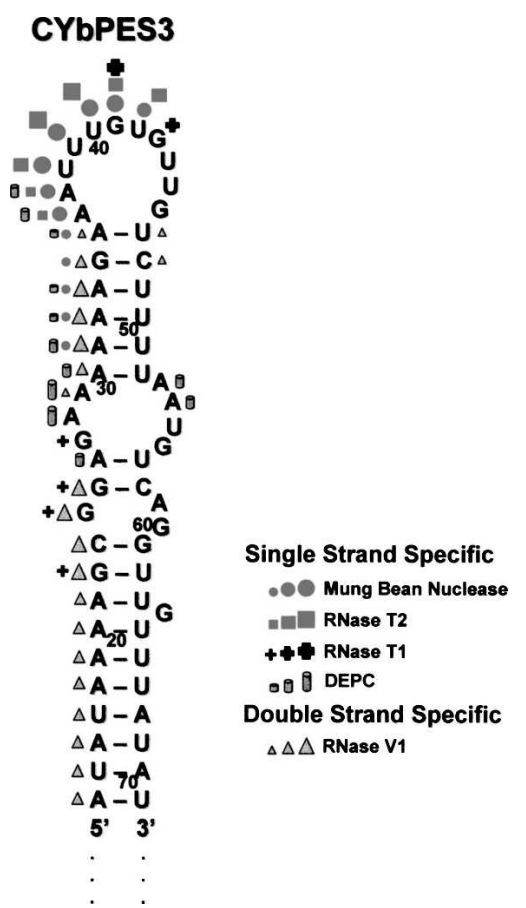

FIGURE 7. Summary figure of CYbPES3 alone from solution structure probing gels that show predicted secondary structure with cleavages from all four nucleases and DEPC using three sizes of symbols to indicate intensity of cleavage. Circles indicate mung bean nuclease (single-strand specific) cleavages, squares indicate RNase T2 (single-strand specific) cleavages, crosses indicate RNase T1 (single-strand guanosine specific) cleavages, cylinders indicate DEPC (single-strand adenosine specific), and triangles indicate RNase V1 (double-strand specific) cleavages.

structure probing experiments, using diethyl pyrocarbonate (DEPC), were performed (Fig. 5). This chemical was chosen because it is reactive with purines and because their reactivity can be monitored via chain scission, a necessity with our cross-linked substrates. DEPC is very sensitive to the stacking of base rings; therefore, adenines within a helix are not reactive. In these experiments, while the anchor is clearly protected, nt A26-A32 are reactive with DEPC, suggesting that this region is in fact single-stranded and is not highly structured (Figs. 5, 6C). Adenosine residues located further upstream (A14-A21) are not reactive, suggesting that this region is helical in nature (Figs. 5, 6C).

In comparing the cleavage patterns when CYbPES3 was paired to its gRNA with and without (NgCYb-558sU) a U-tail, we saw very little difference. Previous cross-linking experiments indicate that the U-tail does interact with the purine-rich region around G25; however, in these experiments the cross-linking efficiency was low, indicating that this interaction is not stable.

\section{CONCLUSIONS}

In this study, we investigated the structure of $\mathrm{NgCYb}-558$ alone and its structure when paired with its cognate unedited mRNA or partially edited mRNA. From our previous structure studies (Leung and Koslowsky 1999), the computer-predicted models suggested that the gRNA stem-loop (A29-U42) is maintained when the initial mRNA/gRNA complex is formed (Fig. 6B). In addition, $3^{\prime}$ cross-linking studies with partially edited substrates suggested that a gRNA stem-loop structure is preserved as editing proceeds through the third editing site via interaction with the U-tail (A36-U53) (Fig. 6C). The results of this study support the predicted models and suggest that the gRNA stem-loop may be an important structural component of the initial editing complex. We hypothesize that the formation of multiple helices surrounding the first few editing sites may allow for tertiary interactions that help stabilize the initial gRNA/mRNA interaction. Increasing the amount of editing increases the number of base pairs within the anchor duplex, and this may negate the need for tertiary interactions during the later stages of the gRNA interaction. Alternatively, the multiple helices may limit the number of potential gRNA/mRNA interaction sites, and this may help increase the accuracy of the editing process. This suggests that the $\mathrm{U}$-tail may enhance the editing process in a number of ways. The U-tail is added post-transcriptionally and has been shown to be unnecessary for in vitro cleavage of editing substrates (Kable et al. 1996; Seiwert et al. 1996; Burgess et al. 1999). However, sequence modifications that disrupt upstream base-pairing interactions severely diminish formation of edited product. Likewise, sequence modifications that increase the stability of the upstream duplex are known to increase the efficiency of in vitro editing, suggesting that the upstream gRNA/mRNA interaction is important (Burgess et al. 1999; Kapushoc and Simpson 1999; Igo et al. 2000; Cruz-Reyes et al. 2001). Previous work in our laboratory using gel shift analyses indicates that the $\mathrm{U}$-tail is very important for stabilization of the interaction of some mRNA/gRNA pairs (Koslowsky et al. 2004). RNAi studies have also shown that when the RNA editing terminal uridylyl transferase (RET1), responsible for adding the U-tail to gRNAs, is down-regulated, there is a decrease in edited mRNAs and inhibited growth of the trypanosome (Aphasizhev et al. 2002). This suggests that the U-tail is necessary for in vivo editing (Gott 2003; Nebohacova et al. 2004). We know that the RNA editing process must involve the formation and disruption of intramolecular helices to form a number of intermediate complexes (Nordgren et al. 2001). Guide RNAs appear to be able to take advantage of U-tail flexibility through the ability of uridines to base-pair with both purine bases. By employing an uridylate tail, the gRNA may increase mRNA/gRNA complex stability, without hampering the U-tail migration needed within the complex during the editing process. In addition, the editing process may take advantage of the special properties of $\mathrm{G}-\mathrm{U}$ base pairs. The G-U base pair has a distinctly different geometry and may locally destabilize helical regions creating 
protein recognition elements (Chow et al. 1992; Batey and Williamson 1996). Editing also creates G-U base pairs, raising interesting possibilities for protein recognition of the edited mRNA/gRNA complex and the recruitment of RNA helicases necessary for multiple gRNA utilization.

We have reported here the structure of the naked RNA for the dynamic $\mathrm{CYb}$ mRNA/gRNA complex. It will be interesting to discover in future studies how much these RNA structures and dynamics change in the presence not only of the editosome proteins but also with the accessory factors assembling and disassembling from the mRNA/ gRNA complex.

\section{MATERIALS AND METHODS}

\section{Oligodeoxyribonucleotides}

All oligodeoxynucleotides (Table 1) were ordered from Integrated DNA Technologies, Inc.

\section{Oligoribonucleotide}

Oligoribonucleotide was ordered from Dharmacon Research, Inc. $\mathrm{U}_{15}$-tail: 5'-UUUUUUUUUUUUUUU-3', 15 nt.

\section{DNA templates and RNA synthesis}

DNA templates of the partial mRNAs: CYbU and CYbPES3 templates were created by ligating two oligodeoxyribonucleotides, the 5' (5'ShortCYb and 5'CYbPES3Short) (Table 1) and $3^{\prime}$ (3'ShortCYb and $3^{\prime}$ CYbPES3Short) (Table 1) halves of the molecules using T4 DNA ligase (Roche) and a complementary DNA bridge (ShortCYb bridge and CYbPES3ShortDNAbridge) (Table 1; Moore and Sharp 1992). The ligated templates were then PCR amplified with T7 and Big SK oligonucleotides (Table 1) and Taq polymerase (Promega) as per the manufacturer's directions. The gRNA constructs (NgCYb558 and NgCYb558(sU)) (Table 1) have been previously described (Leung and Koslowsky 2001b). The mRNA transcripts were synthesized either by T7 RNA polymerase (Ribomax, Promega) according to the manufacturer's directions or in the presence of $5 \mathrm{mM}$ guanosine as described previously (Leung and Koslowsky 2001a). NgCYb-558 and $\mathrm{NgCYb}-558 \mathrm{sU}$ were synthesized using a T7 RNA polymerase using a Ribomax kit (Promega) in the presence (Burgin and Pace 1990; Harris and Christian 1999) or absence of Guanosine 5 '-monophosphorothioate (GMPS) (Biolog Life Science Institutes or Harris Laboratory). If GMPS was incorporated at the $5^{\prime}$ end of the $\mathrm{NgCYb}-558$ transcripts (with and without U-tail), then $20 \mu \mathrm{Ci}$ of $\left[{ }^{32} \alpha \mathrm{P}\right] \mathrm{rATP}$ (Perkin-Elmer) was added for visualization, the rGTP was reduced to $80 \mathrm{nmol}$, and $8 \mu \mathrm{L}$ of $100 \mathrm{mM} \mathrm{MgCl}_{2}$ was added per $80 \mu \mathrm{L}$ reaction. The mRNAs and gRNAs were gelpurified on $6 \%$ and $15 \% 7 \mathrm{M}$ urea acrylamide gels, respectively (Leung and Koslowsky 2001a). The oligoribonucleotide $\mathrm{U}_{15}$-tail was phosphorylated using T4 kinase (Invitrogen) and ligated to $\mathrm{NgCYb}-558 \mathrm{sU}$ using $25 \mathrm{U}$ T4 DNA ligase (Roche) and the $\mathrm{NgCYb}-558$ (sU) bridge (Table 1; Moore and Sharp 1992; Leung and Koslowsky 2001a).

\section{RNA cross-linking and end labeling}

Attachment of p-azidophenacyl bromide (Sigma) to GMPS $\mathrm{NgCYb}-558$ and GMPS NgCYb-558sU transcripts as well as cross-linking of gRNAs and mRNAs was done as described previously (Leung and Koslowsky 1999, 2001a, b). The mRNA (50 pmol of free and 5 pmol of cross-linked mRNA) was 5 '-endlabeled using 50-100 $\mu \mathrm{Ci}$ of $\left[\gamma^{32} \mathrm{P}\right] \mathrm{rATP}$ (Perkin-Elmer) and $\mathrm{T} 4$ Kinase (Invitrogen) as per the manufacturers' directions and gel-purified as above. The gRNA was $3^{\prime}$-end-labeled by ligating $0.5 \mathrm{nmol}$ of $\mathrm{U}_{15}$-tail to $130 \mu \mathrm{Ci}$ of $\left[5^{\prime}-{ }^{32} \mathrm{P}\right]$ cytidine $3^{\prime}, 5^{\prime}-$ bisphosphate (pCp) (Perkin-Elmer) using T4 RNA ligase (New England Biolabs) as per the manufacturer's directions. The labeled $\mathrm{U}_{15}$-tail was ethanol-precipitated, 5'-phosphorylated with T4 Kinase (Invitrogen) according to the manufacturer's directions, and ligated to $\mathrm{NgCYb}-558 \mathrm{sU}$ (no U-tail) using $25 \mathrm{U}$ high concentration T4 DNA Ligase (Roche) and the $\mathrm{NgCYb} 558(\mathrm{sU})$ bridge (Table 1) as previously described.

\section{Structure-specific enzymatic probing}

In these experiments, $150-200 \mathrm{kcpm}$ of labeled RNA sample and $10 \mu \mathrm{g}$ of tRNA were heated to $50^{\circ} \mathrm{C}$, cooled slowly, and incubated at $27^{\circ} \mathrm{C}$ for $20 \mathrm{~min}$. Enzyme was then added to the sample $(0.1 \mathrm{U}$ RNase T1 [Industrial Research, LTD], 0.18 U RNase V1 Cobra

TABLE 1. List of oligodeoxyribonucleotides

\begin{tabular}{|c|c|c|}
\hline Name & Sequence & Length (nt) \\
\hline Big SK & 5'-GGCCGCTCTAGAACTAGTGG-3' & 20 \\
\hline T7 & 5'-AATTAATACGACTCACTATAG-3' & 22 \\
\hline $\mathrm{NgCYb558(sU)}$ & 5'-TTATTCCСТTTATCACCTAGAAATTCACATTGTCTTTTAAATCCСТATAGTGAGTCGTATTAAATT-3' & 65 \\
\hline NgCYb558 & $\begin{array}{l}\text { 5'-AAAAAAAAAAAAAAATTATTCCCTTTATCACCTAGAAATTCACATTGTCTTTTTAATCCCTATAGT } \\
\text { GAGTCGTATTAAATT-3' }\end{array}$ & 80 \\
\hline gCYb558(sU) bridge & 5'-AAAAAAAAAAAAAAATTATTCCСТTTATCACC-3' & 32 \\
\hline 5'ShortCYb & 5'-CTTTCTTTTTTCTCСGCTTTTATATAAAATTTATAACCTATAGTGAGTCGTATTAAATT-3' & 59 \\
\hline 3'ShortCYb & 5'-CCGCTCTAGAACTAGTGGATCCATATATTCTATATAAACAACCTGACATTAAAAGACC-3' & 58 \\
\hline ShortCYb bridge & 5'-GGAGAAAAAAGAAAGGGTCTTTTAATGTCAG-3' & 31 \\
\hline 5'CYbPES3Short & 5'-CAAATTTCTTTTTTCTCCGСТTTTAATATAAAATTTATAACCCTATAGTGAGTCGTATTAAATT-3' & 63 \\
\hline 3'CYbPES3Short & 5'-CCGCTCTAGAACTAGTGGATCCATATATTCTATATAAACAACCTGACATTAAAAGACAACA-3' & 61 \\
\hline CYbPES3ShortDNAbridge & 5'-GGAGAAAAAAGAAATTTGTGTTGTCTTTTAATGTCAG-3' & 37 \\
\hline
\end{tabular}


Venom [Pierce ${ }_{\mathrm{MB}}$ ], $0.4 \mathrm{U}$ RNase T2 [Invitrogen], $1 \mathrm{U}$ MBN [GibcoBRL]). For RNases T1 and T2, aliquots were taken at 5, 10, and 15 min of digestion, and for RNase V1 and MBN, aliquots were taken at 2, 5, and $10 \mathrm{~min}$. The aliquots were immediately phenol/chloroform-extracted, ethanol-precipitated, and then loaded on $12 \%$ or $15 \%$ denaturing acrylamide gels. Reactions were performed in $10 \mathrm{mM}$ Tris ( $\mathrm{pH} 7.5), 100 \mathrm{mM} \mathrm{KCl}, 1 \mathrm{mM}$ $\mathrm{MgCl}_{2}$ for all enzymes except MBN. MBN had buffer conditions of $10 \mathrm{mM}$ Tris ( $\mathrm{pH} 7.5), 10 \mathrm{mM} \mathrm{NaOAc}(\mathrm{pH} 5.0), 0.1 \mathrm{mM}$ ZnOAc, $50 \mathrm{mM} \mathrm{NaCl}, 1 \mathrm{mM}$ L-cysteine, 5\% glycerol, $1 \mathrm{mM}$ $\mathrm{MgCl}_{2}$. RNA sequence ladders were made by denaturing $150 \mathrm{kcpm}$ of labeled RNA and $2 \mu \mathrm{g}$ of tRNA and digesting with $0.07 \mathrm{U}$ RNase T1 and 0.2 U RNase U2 (Industrial Research, LTD) for $10 \mathrm{~min}$ at $55^{\circ} \mathrm{C}$ in the following buffers: $[1 \times$ Buffer I (T1): $19.8 \mathrm{mM}$ NaCitrate (pH 5.0), 1 mM EDTA, 4.2 M Urea, 0.02\% Xylene Cyanol, 0.05\% Bromophenol blue], $[1 \times$ Buffer II (U2): same as above except NaCitrate at $\mathrm{pH}$ 3.5] (buffer recipes courtesy of Dr. Brenda Peculis, NIH, pers. comm.). The gels were fixed, dried, and exposed on a PhosphorImaging screen overnight.

\section{Solution structure probing with chemicals}

For chemical modification and cleavage, the 5'-end-labeled mRNA was annealed to the gRNA by heating to $50^{\circ} \mathrm{C}$ and cooling slowly to $27^{\circ} \mathrm{C}$, where they were held for $30 \mathrm{~min}$ in $50 \mu \mathrm{L}$ of $1 \times$ HE buffer ( $25 \mathrm{mM}$ Hepes at $\mathrm{pH}$ 7.5, $2 \mathrm{mM} \mathrm{MgOAc}, 50 \mathrm{mM} \mathrm{KCl}$, $0.5 \mathrm{mM}$ DTT, $0.1 \mathrm{mM}$ EDTA) and then cross-linked along with controls as above. The mRNA alone samples as well as untreated samples were treated as above without cross-linking. Ten micrograms of tRNA plus $40 \mathrm{U}$ of rRNAsin (Promega) were added to all samples and a no chemical control aliquot $(10 \mu \mathrm{L})$ was taken. Four microliters of $97 \%$ diethyl pyrocarbonate (DEPC; Aldrich) were added and the samples incubated at room temperature (Brunel and Romby 2000). A $20-\mu \mathrm{L}$ aliquot was taken from each reaction at 15 and $25 \mathrm{~min}$. The aliquots were immediately ethanolprecipitated twice in the presence of $0.2 \mathrm{M} \mathrm{NaOAc}(\mathrm{pH} 7.0$ ), followed by a $70 \%$ ethanol rinse. Cross-links and controls were then gel-purified on $6 \%$ acrylamide, $7 \mathrm{M}$ urea gels as described above (Leung and Koslowsky 1999, 2001a, b). Strand scission of all chemical samples was accomplished by incubating samples in $20 \mu \mathrm{L}$ of $1 \mathrm{M}$ Aniline (Sigma-Aldrich) ( $\mathrm{pH} \mathrm{4.5)} \mathrm{for} 10 \mathrm{~min}$ at $55^{\circ} \mathrm{C}$, ethanol-precipitating as above (Brunel and Romby 2000), and analyzed on $15 \%$ denaturing acrylamide gels. T1 RNA sequencing ladders were made as described above. An alkaline hydrolysis ladder of mRNA was generated by incubating 100 $\mathrm{kcpm}$ of RNA and $10 \mu \mathrm{g}$ tRNA in $50 \mathrm{mM} \mathrm{NaHCO} / \mathrm{Na}_{2} \mathrm{CO}_{3}(\mathrm{pH}$ 9.0), $1 \mathrm{mM}$ EDTA ( $\mathrm{pH} \mathrm{8.0)}$ at $90^{\circ} \mathrm{C}$ for $5 \mathrm{~min}$.

\section{ACKNOWLEDGMENTS}

This work was supported by NIH grant AI34155 to D.K. We thank Dr. Ron Patterson, Dr. Charles Hoogstraten, Dr. John Wang, Dr. Sandra Clement, Larissa Reifur, and Melissa Mingler and all other members of the MSU RNA Journal Club for critical reading of the manuscript and helpful discussions, as well as Dr. Brenda Peculis at NIH for sharing her buffer recipes and digestion conditions. We would also like to thank Dr. Michael Harris from Case Western University for samples of GMPS and technical advice.

Received January 4, 2006; accepted March 8, 2006.

\section{REFERENCES}

Adler, B.K. and Hajduk, S.L. 1997. Guide RNA requirement for editing-site-specific endonucleolytic cleavage of preedited mRNA by mitochondrial ribonucleoprotein particles in Trypanosoma brucei. Mol. Cell. Biol. 17: 5377-5385.

Aphasizhev, R. and Simpson, L. 2001. Isolation and characterization of a U-specific $3^{\prime}-5^{\prime}$-exonuclease from mitochondria of Leishmania tarentolae. J. Biol. Chem. 276: 21280-21284.

Aphasizhev, R., Sbicego, S., Peris, M., Jang, S.H., Aphasizheva, I., Simpson, A.M., Rivlin, A., and Simpson, L. 2002. Trypanosome mitochondrial $3^{\prime}$ terminal uridylyl transferase (TUTase): The key enzyme in U-insertion/deletion RNA editing. Cell 108: 637-648.

Aphasizhev, R., Aphasizheva, I., Nelson, R.E., Gao, G., Simpson, A.M., Kang, X., Falick, A.M., Sbicego, S., and Simpson, L. 2003a. Isolation of a U-insertion/deletion editing complex from Leishmania tarentolae mitochondria. EMBO J. 22: 913-924.

Aphasizhev, R., Aphasizheva, I., Nelson, R.E., and Simpson, L. 2003b. A $100-\mathrm{kD}$ complex of two RNA-binding proteins from mitochondria of Leishmania tarentolae catalyzes RNA annealing and interacts with several RNA editing components. RNA 9: 62-76.

Batey, R.T. and Williamson, J.R. 1996. Interaction of the Bacillus stearothermophilus ribosomal protein S15 with 16 S rRNA: II. Specificity determinants of RNA-protein recognition. J. Mol. Biol. 261: 550-567.

Blum, B. and Simpson, L. 1990. Guide RNAs in kinetoplastid mitochondria have a nonencoded $3^{\prime}$ oligo(U) tail involved in recognition of the preedited region. Cell 62: 391-397.

Blum, B., Bakalara, N., and Simpson, L. 1990. A model for RNA editing in kinetoplastid mitochondria: "Guide" RNA molecules transcribed from maxicircle DNA provide the edited information. Cell 60: 189-198.

Brunel, C. and Romby, R. 2000. Probing RNA structure and RNAligand complexes with chemical probes. Methods Enzymol. 318: 3-21.

Burgess, M.L., Heidmann, S., and Stuart, K. 1999. Kinetoplastid RNA editing does not require the terminal 3' hydroxyl of guide RNA, but modifications to the guide RNA terminus can inhibit in vitro $\mathrm{U}$ insertion. RNA 5: 883-892.

Burgin, A.B. and Pace, N.R. 1990. Mapping the active site of ribonuclease P RNA using a substrate containing a photoaffinity agent. EMBO J. 9: 4111-4118.

Chow, C.S., Behlen, L.S., Uhlenbeck, O.C., and Barton, J.K. 1992. Recognition of tertiary structure in tRNAs by $\mathrm{Rh}(\mathrm{phen}) 2 \mathrm{phi3+}$, a new reagent for RNA structure-function mapping. Biochemistry 31: 972-982.

Cruz-Reyes, J., Zhelonkina, A., Rusche, L., and Sollner-Webb, B. 2001. Trypanosome RNA editing: Simple guide RNA features enhance U deletion 100-fold. Mol. Cell. Biol. 21: 884-892.

Feagin, J.E. and Stuart, K. 1988. Developmental aspects of uridine addition within mitochondrial transcripts of Trypanosoma brucei. Mol. Cell. Biol. 8: 1259-1265.

Feagin, J.E., Jasmer, D.P., and Stuart, K. 1987. Developmentally regulated addition of nucleotides within apocytochrome b transcripts in Trypanosoma brucei. Cell 49: 337-345.

Gott, J.M. 2003. Two distinct roles for terminal uridylyl transferases in RNA editing. Proc. Natl. Acad. Sci. 100: 10583-10584.

Harris, M.E. and Christian, E.L. 1999. Use of circular permutation and end modification to position photoaffinity probes for analysis of RNA structure. Methods 18: 51-59.

Hayman, M.L. and Read, L.K. 1999. Trypanosoma brucei RBP16 is a mitochondrial Y-box family protein with guide RNA binding activity. J. Biol. Chem. 274: 12067-12074.

Igo Jr., R.P., Palazzo, S.S., Burgess, M.L., Panigrahi, A.K., and Stuart, K. 2000. Uridylate addition and RNA ligation contribute to the specificity of kinetoplastid insertion RNA editing. Mol. Cell. Biol. 20: 8447-8457.

Kable, M.L., Seiwert, S.D., Heidmann, S., and Stuart, K. 1996. RNA editing: A mechanism for gRNA-specified uridylate insertion into precursor mRNA. Science 273: 1189-1195. 
Kapushoc, S.T. and Simpson, L. 1999. In vitro uridine insertion RNA editing mediated by cis-acting guide RNAs. RNA 5: 656-669.

Koller, J., Muller, U.F., Schmid, B., Missel, A., Kruft, V., Stuart, K., and Goringer, H.U. 1997. Trypanosoma brucei gBP21. An argininerich mitochondrial protein that binds to guide RNA with high affinity. J. Biol. Chem. 272: 3749-3757.

Koslowsky, D.J., Goringer, H.U., Morales, T.H., and Stuart, K. 1992. In vitro guide RNA/mRNA chimaera formation in Trypanosoma brucei RNA editing. Nature 356: 807-809.

Koslowsky, D.J., Kutas, S.M., and Stuart, K. 1996. Distinct differences in the requirements for ribonucleoprotein complex formation on differentially regulated pre-edited mRNAs in Trypanosoma brucei. Mol. Biochem. Parasitol. 80: 1-14.

Koslowsky, D.J., Reifur, L., Yu, L.E., and Chen, W. 2004. Evidence for U-tail stabilization of gRNA/mRNA interactions in kinetoplastid RNA editing. RNA Biol. 1: 28-34.

Leung, S.S. and Koslowsky, D.J. 1999. Mapping contacts between gRNA and mRNA in trypanosome RNA editing. Nucleic Acids Res. 27: 778-787.

2. 2001a. Interactions of mRNAs and gRNAs involved in trypanosome mitochondrial RNA editing: Structure probing of an mRNA bound to its cognate gRNA. RNA 7: 1803-1816.

- 2001b. RNA editing in Trypanosoma brucei: Characterization of gRNA U-tail interactions with partially edited mRNA substrates. Nucleic Acids Res. 29: 703-709.

Lowman, H.B. and Draper, D.E. 1986. On the recognition of helical RNA by cobra venom V1 nuclease. J. Biol. Chem. 261: 5396-5403

Madison-Antenucci, S., Sabatini, R.S., Pollard, V.W., and Hajduk, S.L. 1998. Kinetoplastid RNA-editing-associated protein 1 (REAP-1): A novel editing complex protein with repetitive domains. EMBO J. 17: 6368-6376.

McManus, M.T., Shimamura, M., Grams, J., and Hajduk, S.L. 2001. Identification of candidate mitochondrial RNA editing ligases from Trypanosoma brucei. RNA 7: 167-175.

Missel, A., Souza, A.E., Norskau, G., and Goringer, H.U. 1997. Disruption of a gene encoding a novel mitochondrial DEADbox protein in Trypanosoma brucei affects edited mRNAs. Mol. Cell. Biol. 17: 4895-4903.

Moore, M.J. and Sharp, P.A. 1992. Site-specific modification of premRNA: The 2'-hydroxyl groups at the splice sites. Science 256: 992-997.

Nebohacova, M., Maslov, D.A., Falick, A.M., and Simpson, L. 2004. The effect of RNA interference down-regulation of RNA editing 3 '-terminal uridylyl transferase (TUTase) 1 on mitochondrial de novo protein synthesis and stability of respiratory complexes in Trypanosoma brucei. J. Biol. Chem. 279: 7819-7825.

Nordgren, S., Slagter-Jager, J.G., and Wagner, G.H. 2001. Real time kinetic studies of the interaction between folded antisense and target RNAs using surface plasmon resonance. J. Mol. Biol. 310: $1125-1134$
Panigrahi, A.K., Gygi, S.P., Ernst, N.L., Igo Jr., R.P., Palazzo, S.S Schnaufer, A., Weston, D.S., Carmean, N., Salavati, R., Aebersold, R., et al. 2001a. Association of two novel proteins, TbMP52 and TbMP48, with the Trypanosoma brucei RNA editing complex. Mol. Cell. Biol. 21: 380-389.

Panigrahi, A.K., Schnaufer, A., Carmean, N., Igo Jr., R.P., Gygi, S.P., Ernst, N.L., Palazzo, S.S., Weston, D.S., Aebersold, R., Salavati, R., et al. 2001b. Four related proteins of the Trypanosoma brucei RNA editing complex. Mol. Cell. Biol. 21: 6833-6840.

Panigrahi, A.K., Allen, T.E., Stuart, K., Haynes, P.A., and Gygi, S.P. 2003a. Mass spectrometric analysis of the editosome and other multiprotein complexes in Trypanosoma brucei. J. Am. Soc. Mass Spectrom. 14: 728-735.

Panigrahi, A.K., Schnaufer, A., Ernst, N.L., Wang, B., Carmean, N., Salavati, R., and Stuart, K. 2003b. Identification of novel components of Trypanosoma brucei editosomes. RNA 9: 484-492.

Pelletier, M. and Read, L.K. 2003. RBP16 is a multifunctional gene regulatory protein involved in editing and stabilization of specific mitochondrial mRNAs in Trypanosoma brucei. RNA 9: 457-468.

Riley, G.R., Corell, R.A., and Stuart, K. 1994. Multiple guide RNAs for identical editing of Trypanosoma brucei apocytochrome b mRNA have an unusual minicircle location and are developmentally regulated. J. Biol. Chem. 269: 6101-6108.

Rusche, L.N., Huang, C.E., Piller, K.J., Hemann, M., Wirtz, E., and Sollner-Webb, B. 2001. The two RNA ligases of the Trypanosoma brucei RNA editing complex: Cloning the essential band IV gene and identifying the band V gene. Mol. Cell. Biol. 21: 979-989.

Schmid, B., Riley, G.R., Stuart, K., and Goringer, H.U. 1995. The secondary structure of guide RNA molecules from Trypanosoma brucei. Nucleic Acids Res. 23: 3093-3102.

Schnaufer, A., Panigrahi, A.K., Panicucci, B., Igo Jr., R.P., Wirtz, E., Salavati, R., and Stuart, K. 2001. An RNA ligase essential for RNA editing and survival of the bloodstream form of Trypanosoma brucei. Science 291: 2159-2162.

Seiwert, S.D. and Stuart, K. 1994. RNA editing: Transfer of genetic information from gRNA to precursor mRNA in vitro. Science 266: 114-117.

Seiwert, S.D., Heidmann, S., and Stuart, K. 1996. Direct visualization of uridylate deletion in vitro suggests a mechanism for kinetoplastid RNA editing. Cell 84: 831-841.

Simpson, L., Aphasizhev, R., Gao, G., and Kang, X. 2004. Mitochondrial proteins and complexes in Leishmania and Trypanosoma involved in U-insertion/deletion RNA editing. RNA 10: 159-170.

Stuart, K.D., Schnaufer, A., Ernst, N.L., and Panigrahi, A.K. 2005. Complex management: RNA editing in trypanosomes. Trends Biochem. Sci. 30: 97-105.

Vanhamme, L., Perez-Morga, D., Marchal, C., Speijer, D., Lambert, L., Geuskens, M., Alexandre, S., Ismaili, N., Goringer, U., Benne, R., et al. 1998. Trypanosoma brucei TBRGG1, a mitochondrial oligo(U)-binding protein that co-localizes with an in vitro RNA editing activity. J. Biol. Chem. 273: 21825-21833. 